This is an accepted manuscript of an article published in Journal of Computer Assisted Learning on 13/05/2010, available online: https://doi.org/10.1111/j.1365-2729.2010.00347.x

\title{
The strengths, weaknesses, opportunities and threats of using social software in higher and further education teaching and learning
}

\section{A. Schroeder ${ }^{\star}$ S. Minocha \& C. Schneider}

Social software is increasingly being used in higher and further education to support teaching and learning processes. These applications provide students with social and cognitive stimulation and also add to the interaction between students and educators. However, in addition to the benefits the introduction of social software into a course environment can also have adverse implications on students, educators and the education institution as a whole, a phenomenon which has received much less attention in the literature. In this study we explore the various implications of introducing social software into a course environment in order to identify the associated benefits, but also the potential drawbacks. We draw on data from 20 social software initiatives in UK based higher and further education institutions to identify the diverse experiences and concerns of students and educators. The findings are presented in form of a SWOT analysis, which allows us to better understand the otherwise ambiguous implications of social software in terms of its strengths, weaknesses, opportunities and threats. From the analysis we have derived concrete recommendations for the use of social software as a teaching and learning tool.

\section{Introduction}

Social software applications such as wikis, blogs, and social networking sites have received widespread attention for their increasing use in the higher education domain. A number of reports 
in the last years have shown how social software applications positively contribute to a wide range of teaching and learning practices (e.g. JISC, 2009). For example, students use blogs as online reflective diaries to demonstrate their individual learning progress and understanding to the educator and fellow students and hereby increase their own understanding of the subject domain (Du \& Wagner, 2007); student teams or entire courses use wiki applications to collaboratively create course-related content that is continuously refined and updated throughout the development of the course (Trentin, 2009); social networking sites such as Facebook allow students to develop campus-based social capital (i.e. important relationships) and social support networks which facilitate their integration into university life (Ellison, Steinfield, \& Lampe, 2007).

Social software applications enable new forms of community based collaborative learning (McLoughlin \& Lee, 2007): by providing a platform for many-to-many interactions social software applications, such as wikis, social networking, and bookmarking sites, allow students to learn interactively and collaboratively. Although the benefits of such student based learning concepts have been discussed for a long time (e.g. Steffe \& Gale, 1995), their implementation was often held up by practical issues such as the difficulties of arranging for meaningful and lasting interactions among larger student numbers (Garrison \& Arbaugh, 2007). As social software allows large numbers of students to not only present their own insights but also to consolidate and refine each other's contributions, the enthusiasm about the potential impact of these applications on higher education teaching and learning seems to be well justified.

With the increased adoption of social software applications in education practice, a growing body of research has emerged which investigates the benefits of these tools. However, with the notable 
exception of (Cain, 2008) and (Chu \& Meulemans, 2008), the existing research efforts often seem to lack a critical perspective such as considering the risks associated with the adoption of these social software tools for the individual student, the course, or the institution as a whole. While the use of social software on the Web has been linked to spamming (Brown, Howe, Ihbe, Prakash, \& Borders, 2008), stalking (Gross, Acquisti, \& H. John Heinz, 2005), or even cyber-bullying (Mann, 2008) little insights have been gained on the risks and downsides of these applications in the educational context. Social software has the potential to significantly add to teaching and learning practices, but in order to leverage these benefits and to use the diverse applications in a sustainable way, educators need to be aware of the risks the adoption of such tools can create, so as to be able to mitigate these risks.

In this paper, we aim to provide a balanced evaluation of social software by systematically identifying the strengths, weaknesses, opportunities, and threats of such initiatives in the higher and further education contexts. With data collected from 20 UK-based social software initiatives, our analysis not only focuses on the direct benefits and drawbacks for teaching and learning but also focuses on the broader implications of such initiatives for the educational institutions. In addition to providing a systematic treatment of the diverse implications of social software, we use the analysis as the basis for a discussion of strategies and measures that can assist higher education institutions and individual educators in the risk-conscious implementation of such applications.

The present paper is structured as follows. We first describe the role of information and communication technology in the higher education domain in general, and the implications of social software, in particular. We then present a brief overview of the SWOT framework, a 
framework widely used for systematic evaluation of strengths, weaknesses, opportunities, and threats of organisational initiatives. We then detail the process of data collection and the methods for analysis. The findings are then presented in the form of a SWOT framework and discussed with regards to the strategic implications and possible solutions of introducing social software into a course environment. The paper concludes by highlighting its core contributions and identifying avenues for future research.

Terminology: The term 'social software initiative' in this paper implies a project or a learning activity or a situation where a social software application is employed. We have used the term 'educator' to imply any colleague (tutor, lecturer or an instructional designer) who has adopted social software tool(s) in an educational context and led the initiative. The term 'student' implies the learner in the social software initiative.

\section{Social software in Higher education}

Higher education has a long tradition in using information and communication technology. As early as in the 1970s, institutions had started to embrace electronic media such as audio tapes or radio broadcasting as alternative channels for the distribution of learning materials. These electronic media channels allowed the higher education sector to meet an increasing demand for education and to overcome the time and place constraints of traditional lecture based course delivery (Gerhard \& Mayr, 2002). The proliferation of the Internet in the 1990s has provided a significant impetus for web-based innovations in education. Web-based e-learning has emerged as an interactive form of learning emphasising on-demand provision of learning materials on the Web, flexible blending 
of teaching content along with face-to-face teaching, and ongoing interaction between students and educators through web-based environments (Romiszowski, 2004).

In today's universities most teaching is supported by information and communication technology, largely in the form of Learning Management Systems (LMS) (Dalsgaard, 2006). LMS's, such as Blackboard and Moodle, are hosted by the individual Institutions where they form an integral part of the overall course management. These applications provide courses with virtual notice boards, document repositories and collaboration tools such as virtual white-boards and discussion forums. As these applications provide secure access rights and audit trails they can also form part of the formal learning assessment. To date, LMS software provides the main platform for the integration of online media into traditional face-to-face course environments.

The prospect of enhancing teaching and learning practices has led educators to also introduce dedicated social software applications into the course environment. Social software applications such as blogs, wikis and social networking sites describe a new genre of web-based applications enabling new forms of user participation and collaboration on the internet (Parameswaran \& Whinston, 2007). These applications allow users to create highly dynamic content, often created in collaborative ways with peer-based quality assurance. Early forms of social software tools such as discussion boards date back to the origins of the Web; others, such as blogs, social networking sites and wikis, only started to become popular in early 2000, but have gained widespread acceptance in social, educational and business contexts; yet others, such as social book-marking tools (e.g. Delicious) and micro-blogging applications (e.g. Twitter), are still being discovered by the mainstream Internet user. Although Institution-based LMS's often provide some basic social 
software functionalities (such as discussion forums, wikis and blogs), they are often considered to be too rigid and formalised in their structures (Dron, 2006) and do not cater well for these highly dynamic initiatives. Educators, therefore, frequently choose dedicated applications or even public internet-based applications as the platform for their social software initiatives.

Several studies have shown how the underlying functionalities of social software can add value in an educational environment. The applications can contribute to cognitive stimulation, relational exchanges and facilitation of the learning process, all of which are critical for the educational experience of a student (Garrison, Anderson, \& Archer, 1999). Wikis for example can serve as platforms for knowledge integration which directly contributes to the students' cognitive development (e.g. Pena-Shaff \& Nicholls, 2004; e.g. Trentin, 2009). Another example is the use of social networking tools which allows students to form campus-based social capital and has been even linked to their psychological well-being (Ellison et al., 2007). A third example is the use of discussion boards which not only provides a platform for knowledge exchange among students (Pena-Shaff \& Nicholls, 2004) but also allows the educators to observe and guide the student interactions (Dennen, 2005). Based on their underlying capabilities the different social software applications have the potential to directly contribute to teaching and learning processes and the students' educational experience.

\section{Data collection and analysis}

Introducing social software into a course environment is a complex initiative as it involves not only educational but also technical considerations. It is therefore critical to understand the diverse implications of adopting social software tools. To disentangle these complex issues we employ SWOT analysis as a guiding framework. A SWOT framework is generally used to systematically 
characterise a particular situation with regards to its internal strengths and weakness as well as its external opportunities and threats. Such a systematic characterisation allows for the identification of appropriate strategies for leveraging the strengths, addressing the weaknesses, exploiting the opportunities and mitigating the threats. As SWOT analysis has been successfully used for assessing information technology projects (Sabbaghi \& Vaidyanathan, 2004) as well as for evaluating public sector initiatives (Janssen, 2002) and we have applied it in our research as a guiding framework for our social software investigations.

In order to identify the individual SWOT factors we collected data from 20 social software initiatives following established methods for multiple case research (Miles \& Huberman, 1994). Case selection was based on a criteria based selection strategy to ensure consistency and quality of the cases: 1) the social software applications had to be available in the public domain (to ensure that the cases investigated are relevant to a wider audience); 2) the social software applications had to be used to support and engage learners (to ensure that the applications considered from part of the pedagogy, and not just for the administration of a course); 3) the social software applications had to be in place for more than one semester of the course (to ensure ample experience of its use and perhaps having already conducted some student-evaluations). A list of the social software initiatives considered is provided in the Appendix ${ }^{1}$.

Data was collected by a team of investigators who visited the respective institutions to conduct semi-structured interviews and focus groups with educators and students involved in the social

\footnotetext{
${ }_{1}^{1}$ Detailed descriptions of the individual social software initiatives can be accessed at this link: http://tinyurl.com/5a8zu3.
} 
software initiative. A common interview pack across all the investigators focused on the nature of the social software initiative as well as its perceived benefits and drawbacks. Overall, the team conducted and transcribed 83 interviews and 5 focus groups with differing numbers of interviewees per case due to different levels of access to interview participants. For each social software initiative, we developed case descriptions to integrate the collected data and illustrate the relevant details. Case descriptions were submitted to key participants to verify the accurate representation of their social software initiative before the data analysis.

Data was analysed following a thematic analysis method (Braun \& Clarke, 2006). Relevant themes and sub-themes concerning the implications of social software were identified through iterative reviews of the case descriptions and ancillary data. To ensure its reliability three members of the research team were involved in the two-staged analysis process. Members first carried out an independent analysis of the data before embarking on a joint analysis where the independently identified themes were consolidated and prioritised. The identified themes and sub-themes concerning the diverse implications of the social software are basic factors which we have presented using the SWOT framework.

\section{Implications of social software}

The findings of our data analysis are categorised in form of a SWOT framework. When using a SWOT framework one needs to clearly identify the unit of analysis and its boundaries as the categories strengths and weaknesses describe the internal characteristics, and the categories opportunities and threats describe the external characteristics of the situation under analysis. In our research context the higher or further education course, as the nucleus of social learning, forms the unit of analysis for the SWOT framework with the course boundaries defining the internal and 
external environment. The categories, strengths and weaknesses, summarise the direct implications social software has on teaching and learning within the boundaries of the course. The categories, opportunities and threats, summarise the implications social software has on aspects of teaching and learning in relation to the wider external environment of the course (i.e. university environment, wider public). The most prominent factors for each SWOT category are presented below in the Tables 1 to 4 and subsequently discussed with representative examples from our case studies. The examples and sources in the table are referenced by acronyms which identify the originating case studies as listed in the appendix. Following the basic notion of SWOT analysis, avenues are discussed for each category on how the strengths of social software can be leveraged and opportunities can be exploited, as well as the weaknesses addressed and the risks mitigated.

\section{Strengths of social software}

Our analysis of the case data identified a number of strengths through which social software supports teaching and learning (see Table 1). The ability of social software to contribute to the building of social relationships, to improve learning, and to enhance communication between students and educators stood out among the different strengths identified.

\section{- Building of social relationships}

Respondents from a large number of cases outlined how social software helped students to build valuable relationships within a course or program. By accessing each other's blogs and social networking profiles, students were able to overcome relational barriers, which in turn contributed to the development of a community spirit among the students. An example is provided by the case of Nottingham Trent University [NTU] where the use of blogs helped students to provide each other with social support on a teacher training course. Students in this course were placed in schools 
across a large geographical area and had little opportunity to develop a support network. The introduction of individual blogs reportedly contributed to such a community development as it provided students with an opportunity to share their experiences and to provide each other with emotional support. Our observations support Garrison's notion of social presence (Garrison \& Akyol, 2009) which implies that despite being largely text-based tools without verbal cues, social software facilitates the building of social relationships, personal connection, and sense of belonging.

\section{- Improved learning}

The ability to introduce new and improved learning practices has emerged from our data as another important strength of social software. Student's individual contributions in the social software environment often triggered reactions by fellow students in form of feedback or challenging comments which are important elements of collaborative and reflective learning

(Johnson \& Aragon, 2003). At Birmingham City University [BCU1] students used wikis to record and present small group discussions to a wider audience which would read and add comments. Collecting peer-based feedback from a larger audience allowed the students to integrate new perspectives into their group work and reportedly encouraged them to be more reflective in their learning. Social software was also found to contribute to independent learning practices as the initially 'content-free' applications encourage students to create and organise their own learning resources. At Open University [OU4] students used social book-marking tools to collaboratively create and annotate a shared bibliography of relevant websites and thereby created and prioritised their own learning resources. In our research we observed that, in addition to gaining expertise in 
their respective subject matter, students also developed skills related to the particular use of the social software applications.

\section{- Enhanced communication between students and educators}

Enhanced communication between students and educators was identified as another major strength of social software. By following the interactions and contributions of the students in an online space, educators reported how they could intervene, facilitate or provide direction. Providing avenues for educators to interact with students and facilitate their learning directly contributes to the overall learning experience (Garrison \& Akyol, 2009). An illustrative example is provided by the case of Portsmouth University [PU] where the micro-blogging application Twitter was used for the communication between the educator and student project teams. It was reported how the spontaneous "chit-chat" environment of Twitter contributed to more informal and more frequent communication patterns which added to the quality of the projects. As informal communication between students and educators is an important element of the overall learning experience (Mottet, Martin, \& Myers, 2004) the ability of social software to facilitate such a form of interaction is significant. During the interviews several educators also explained that the use of social software in their course helped them to better understand the student's needs as the applications allowed them to observe the interactions among the students and their particular areas of contributions. 
Table 1. Strengths of social software

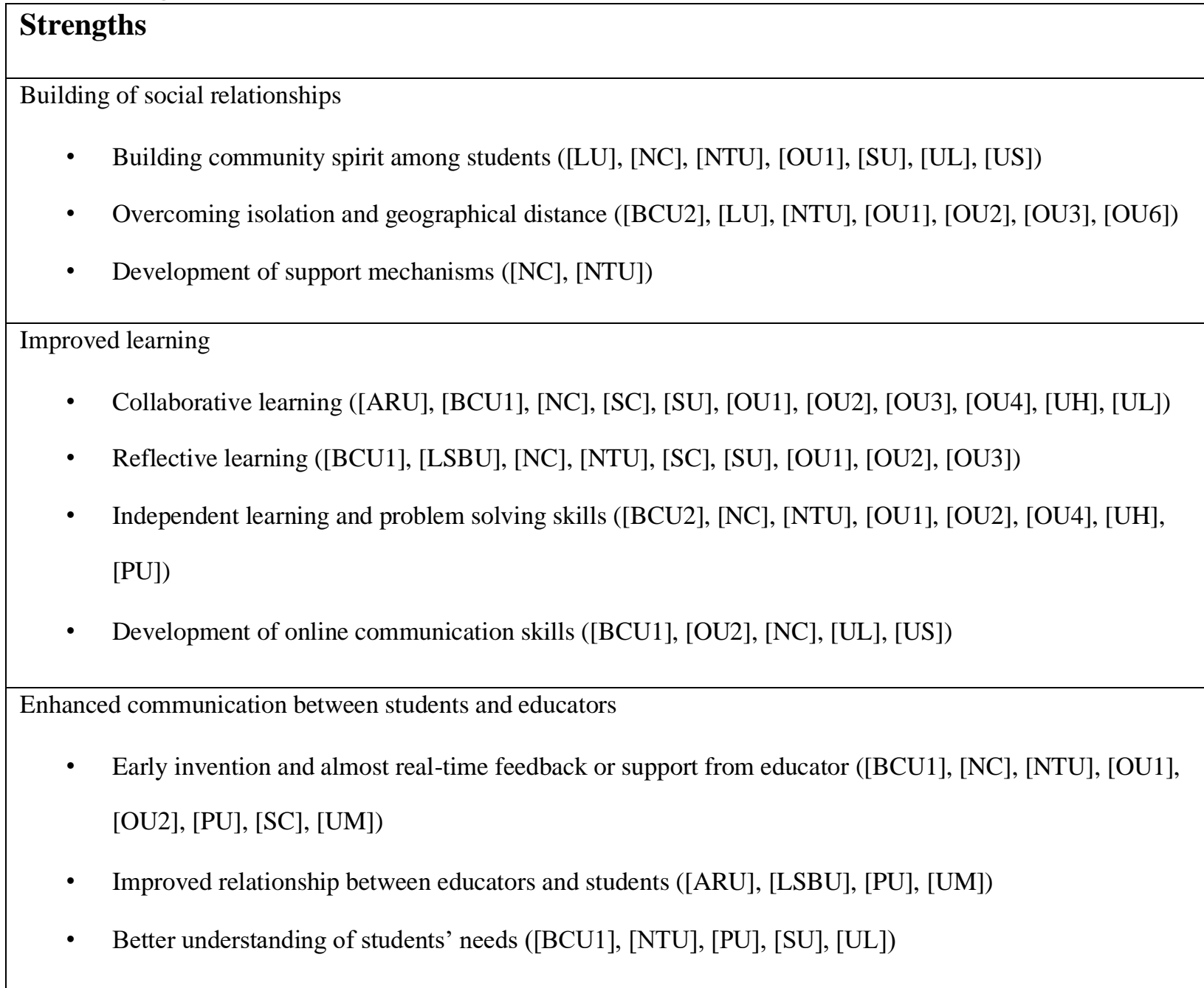

\section{Leveraging the strengths of social software}

Social software tools have a wide range of capabilities, for example, building social relationships (e.g. social networking sites), reflective learning (blogs), sharing of resources (photo-sharing sites or bookmarking sites), and collaborative authoring (e.g. wikis). It is important to note that the inherent strengths of social software do not emerge by themselves. The educators in our study discussed how the choice of tools and the activity design should match with the learning outcomes of the activity or course. Further, to overcome the limitations of individual tools, it can even be necessary to combine different tools as in the case of Open University [OU3] where the 
collaborative authoring environment (wiki) was considered insufficient for more complex groupbased decision making and therefore additional communication tools such as discussion forums and instant messaging had to be employed. Our study also shows that it is not enough to set up the activities and leave it to the students to collaborate and share. In order to create a dynamic collaborative environment, it is important to pro-actively foster the use of these tools as the limited time frame of a course does not allow sufficient time for the social dynamics to establish by themselves.

\section{Weaknesses}

In addition to the strengths our analysis has identified a range of weaknesses of using social software in a course environment (see Table 2). Specific weaknesses which were widely pointed out by our respondents include the high workload, the limited quality of interaction, as well as uncertainty about the ownership and assessment issues.

\section{- Workload issues}

The introduction of social software creates additional workload for students as well as educators. Our data has shown how students, at times, experience the use of social software as an extra task in addition to their course requirements. Being involved in the ongoing interactions in a social software environment can impact the flexibility and independence of the individual student.

Especially in the case of a distance education course at Open University [OU2] students were concerned that the ongoing interaction on the wiki would limit the flexibility of their part-time study arrangements. Also a large fraction of educators from our case institution have described how their social software initiatives required a considerable amount of time, especially when the initiative was carried out the first time. Setting up the application, administering the users, 
monitoring their contributions all created workload which was in addition to the running of the actual course. This workload issue is further aggravated by the fact that most social software initiatives in our case organisations were carried out by individual educators with little or no provision of resources from the institution.

\section{- Perceived limitations in the quality of interaction}

Our data has also shown that social software exhibits constraints related to communication and collaboration practices. Students repeatedly pointed to the difficulties these social software environments create for maintaining proper forms of interaction. Whereas a 'real world' environment provides a large number of cues to judge if a particular form of interaction is appropriate, the provision of these cues in an online environment is very limited (Dennis \& Kinney, 1998). As not all students had the same level of experience in the use of these applications, misunderstandings and difficulties of interactions arose with students reporting concerns about finding the right tone for providing constructive feedback in these environments (e.g. [OU1]). At London South Bank University [LSBU] students were concerned with the poor level of interaction on their blogs as fellow students' feedback was often concentrated on a few blogs while others did not receive any comments. Issues in the quality of interaction is of particular importance in situations where the course involves no face to face interaction; overall we observed that challenges in terms of online socialisation was less evident in those social software initiatives which had a considerable level of face to face interaction.

\section{- Uncertainty about ownership and assessment issues}

Content within a social software application is largely created through the interaction between individuals. Even in the case of blogs, which are largely maintained by individuals, the true value 
is derived from the comments of visitors or readers and the hyperlinks with other blogs (Kumar, Novak, Raghavan, \& Tomkins, 2004). Such a commons based approach to content (Benkler, 2002) creates difficulties in a teaching and learning environment where assessment is often based on the achievements of individuals or defined groups. In several of our cases students expressed concerns that their individual contribution would not be identified; such as in the case of the University of Hertfordshire [UH] where concerns were voiced that the integrative nature of the wiki would allow fellow students to hide behind the contributions of others. Also educators in our cases expressed some level of uncertainty about the best form of assessing students work in a collaborative environment: concerns involve practical considerations (e.g. peer-assessment versus assessment by the educator) but also pedagogical considerations related to the paradox of teaching collaborative learning while assessing individual contributions [BCU1].

Table 2. Weaknesses of social software

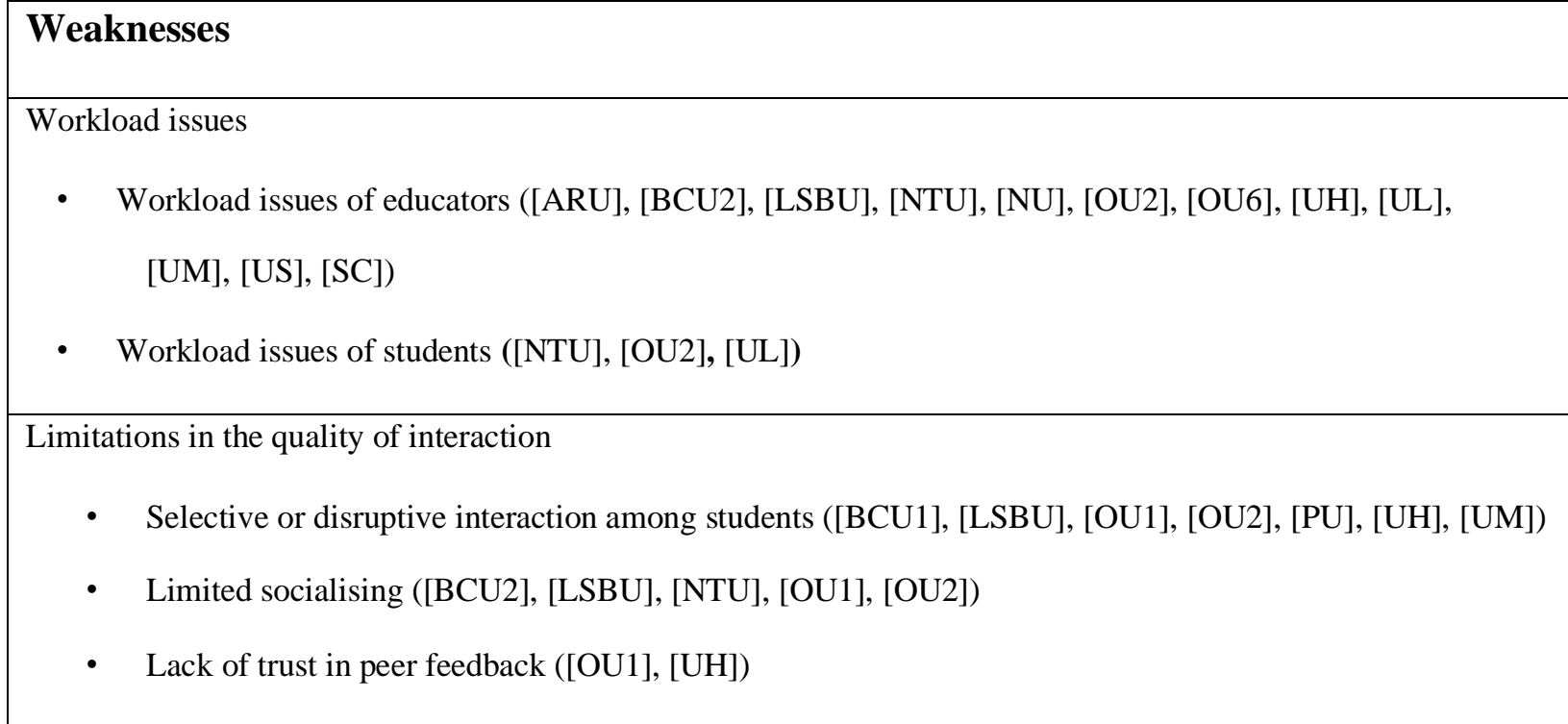


Uncertainties of ownership and assessment

- Assessment of collaborative activities ([ARU], [BCU1], [NTU], [OU1], [OU2], [SC], [SU], [UH], [UL], [US])

- Ownership issues of content in public or collaborative spaces ([OU4], [SC], [SU], [UH], [UL])

\section{Addressing the weaknesses}

The ability to leverage the strengths of social software is highly dependent on the extent to which the inherent weaknesses of these applications are addressed. As the workload issue affects both students and educators, addressing it should be considered highest priority in order to sustain a social software initiative. To address the workload impact on the student, it is critical to consider the intricacies of these social software collaboration environments and to set the tasks and expectation levels accordingly. The workload issue for students and educators was a particular concern in the history course at University of Leeds [UL] and therefore a student helper became involved in the social software initiative early on. The interviewees from this particular initiative not only highlighted how the student could assist in the administration and monitoring of the application, but also highlighted how the input from the student significantly helped in appropriately targeting the range of tasks and expectation levels.

To address the ownership and assessment issues as well the concerns caused by the limited interaction requires students and educators to carefully establish norms and protocols of collaboration. Although in a large number of our cases students were provided with specific instructions before the launch of the social software initiative, these training elements were largely focused on the use of the application, with little focus on the particular communicative constraints of the applications and the protocols for their efficient use. However, social software constitutes a 
novel interaction environment, bringing about new collaboration practices and distinctive ownership concepts which need to be actively discussed and agreed upon at the outset of a social software initiative.

\section{Opportunities}

The external opportunities which are provided by social software are summarised in Table 3 . The opportunities that stood out most in our analysis are the showcasing of student work and the creation of ongoing communities.

\section{- Showcasing work}

Although the social software initiative is created within a course environment, public internet based applications are used as platforms to enable the student-interaction. Therefore, assignments which are created as part of the course can therefore easily be accessed by users from the wider public. Not being restricted to the course environment allows students and educators to easily showcase their work to a large audience and even involve the wider public in the task. In several of our cases it was reported how the opportunity to showcase their work to a wider audience was appreciated by students and how the prospect of a public audience encouraged students to put extra effort in the task completion. In the case of University of Salford's [US] course on sound and videotechnology, the showcasing of student work even led to students receiving work offers from established companies.

\section{- Creating and maintaining communities}

When using social software applications, students obtain logins, create profiles and in some applications even form relationships (e.g. social networking). Once such online profiles are created, 
they will often be used outside the course environment or even after the course has been completed. In our cases we could observe how students and educators maintained their initial course-based online presence to further develop their own communities which lasted well beyond the duration of the course. Students of the Open University photography class [OU1], for example, continued to use a photo-sharing application which was introduced in the course to continue to present their work to their former fellow students and to hereby obtain valuable feedback. At the School of Dentistry, University of Manchester [UM], the use of blogs and social networking applications helped to maintain an alumni-like community among the students with ongoing information sharing and relational exchanges. In these cases, the introduction of the social software tool provided students with an incentive to establish their communities and modes of interaction and, once the course was finished, the communities took a life on their own as the students appreciate the value of their interactions with others.

Table 3. Opportunities of social software

\section{Opportunities}

Showcasing work to the public

- Incentivising students to create high quality ([LSBU], [OU1], [SC], [UL])

- Contribute to employability ([ARU], [LSBU], [OU4], [US])

Creating and maintaining communities

- $\quad$ Development of alumni communities ([OU1], [UM])

- Social software tools help to foster cross-institutional collaborations ([ARU], [NC])

\section{Exploiting opportunities}

The use of social software permeates the traditional boundaries of the course which creates a range of opportunities for presenting student work to the public and for initiating far reaching communities. Showcasing the student work creates significant opportunities for educational 
institutions to gain additional exposure and to add to the reputation of a particular course or study programme. However, in order to systematically exploit these opportunities the learning activities and the set up of the applications need to be specifically prepared for these endeavours. It is important that the activities and expectations are set in a way that the deliverables constitute contributions which can be understood and appreciated by the interested public. Such a public display of student work can further be enhanced by specifically linking prospective students or employers to the collaboration environments in which the students interact and contribute. While none of our cases followed such an explicit promotion of the students work examples of the Columbia University Social Justice Movements ${ }^{2}$ course and the Bowdoin University Romantic Audience Project ${ }^{3}$ shows how Universities can make use of such showcasing opportunities.

\section{Threats}

The ability of social software to bridge the boundary between the course and its wider environment not only creates opportunities but introduces a number of threats to the social software initiative (see Table 4). The threats which stood out most from our data focus on the difficulty of ensuring support and reliability of the applications, and the implications of their illegitimate use.

\section{- Support and reliability of the applications}

Social software applications which are externally hosted do not form part of the portfolio of elearning tools of the educational institution. Consequently, any institution's IT department is limited in the extent to which they can provide support and maintenance of the applications or even ensure their availability. These limitations in controlling the social software application have to be

\footnotetext{
${ }^{2} \mathrm{http} / / /$ socialjustice.ccnmtl.columbia.edu

${ }^{3}$ http://ssad.bowdoin.edu:8668/space/snipsnap-index
} 
taken seriously; in fact, some of our case organisations reported of actual issues which were related to the externally hosting situation. In the case of London South Bank University [LSBU], for example, where a photo-sharing website was used for students to upload and present their photography assignments, a student found his user account suspended and images deleted. Most of our respondents voiced at least some level of concern regarding the reliability of the tools in the public domain. Once the social software application becomes an integral part of a course and involves the creation of marked assignments, any kind of disruption (such as downtime, corrupted data, or slow access) on which the institution has no control can have far reaching implications for the course. Adopting such publicly hosted social software applications introduces a risk into the course environment which the educator or IT support are largely unable to control.

\section{- Illegitimate use}

Another important threat which has emerged during data analysis involves the potential for using the social software application for illegitimate purposes. This illegitimate form of use may be caused by students but also by members of the public. Students may potentially use their access to the social software application to create inappropriate content or engage in devious behaviour. Such an activity could certainly affect the credibility of the educational institution and therefore needs to be considered a considerable threat. Further, external members of the public may potentially enter a course-based student interaction and expose students to inappropriate content or devious behaviour. Such a scenario might also create serious implications for the institution, the educator(s) involved, and the students, and needs to be considered a serious threat. While a number of educators in our case organisations were very concerned about these threats, none of the cases reported of any such incidents taking place. 
Table 4. Threats of social software

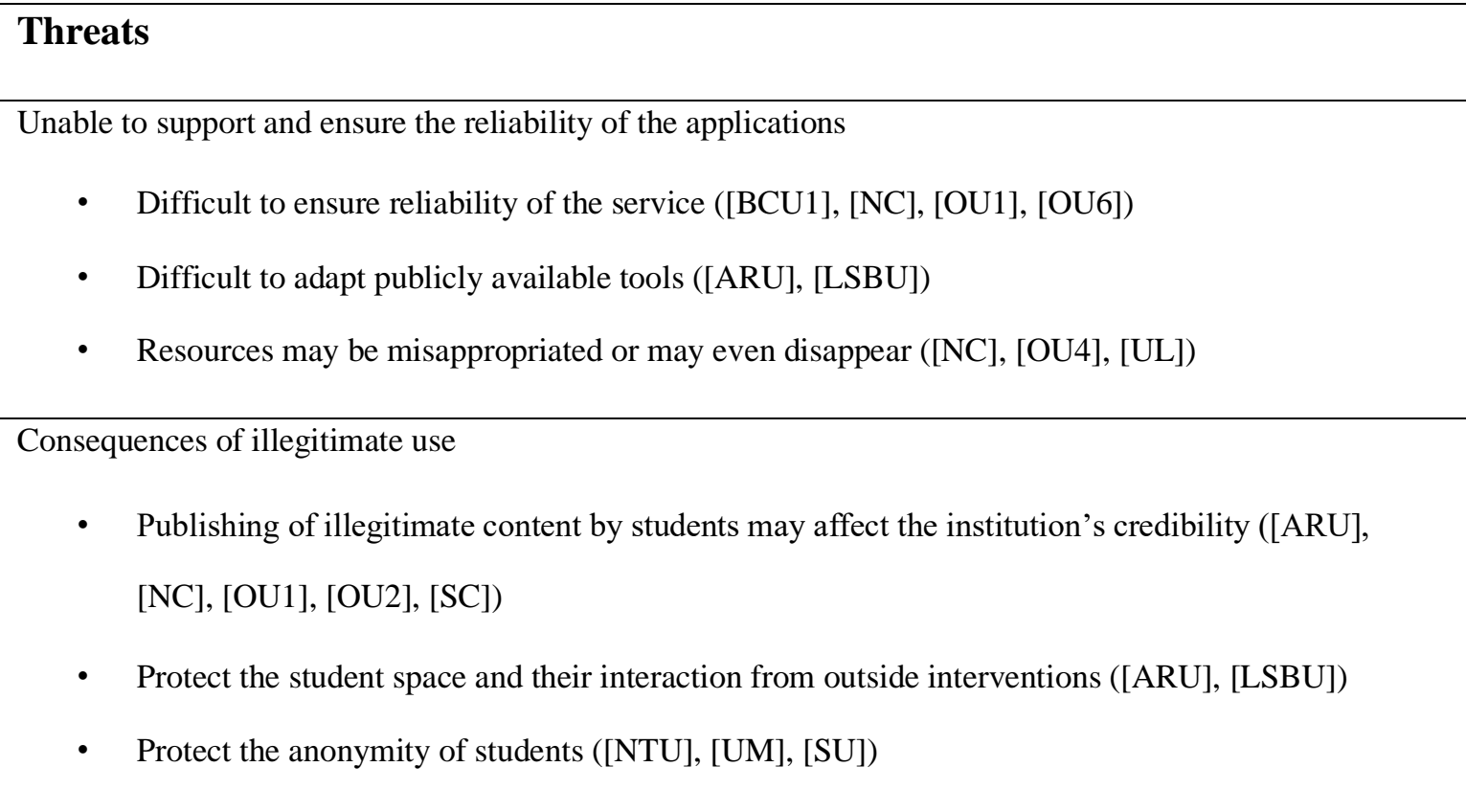

\section{Mitigating the threats}

Although the introduction of social software tools into course environments can expose institutions to considerable risks, little guidance is generally provided to the initiating educators. Only in five of our twenty cases the institutions reported of explicit attempts to safeguard the issues of a social software initiative. The safeguarding focused on reminding the students of the existing institutions computing code of conduct ([OU2], [ARU]) or the development of policies explicitly targeted to the social software initiative [UW]. Other institutions were less formal and asked the students to formulate policies ([NC], [OU1]) or simply informed them about the risks. Interestingly, we encountered no initiative which created specific safeguards to protect students from outside harm, although these threats are well known. We found that social software initiatives are largely initiated and carried out by individual educators with little guidance and support being provided by their institutions. However, to mitigate these risks, institution-level support and interventions will help 
to manage the threats and to initiate a discourse which engages students, educators and IT personnel to formulate sound and practical solutions and guidelines.

\section{Conclusions}

Social software has created considerable enthusiasm in the further and higher education domains. Integrating these applications into learning and teaching practices has the potential to trigger significant educational innovations as they enable new forms of interactive and collaborative learning. However, discussing social software applications only with a focus on their possible benefits ignores the downsides and potential risks associated with these technologies. For fully exploiting the benefits that social software applications provide, there is a need to consider the risks and downsides which can jeopardise the social software initiative or even cause legal implications for the hosting institution.

In order to integrate and maintain social software applications into teaching and learning and to sustain these initiatives, it is important to be aware of the implications of adopting social software. To provide a balanced assessment, we have conducted an empirically-grounded investigation to determine the benefits and possible concerns associated with the use of social software tools in learning and teaching. We drew on data from 20 UK based social software initiatives to identify the diverse implications of these applications in the further and higher education contexts. We then presented the data in form of a SWOT framework which allowed us to systematically discuss the diverse implications and to identify suitable approaches to actively address these.

Our present work contributes to the growing body of research on social software as well as to the practical aspects of its implementation. We have contributed to research by empirically analysing 
the consequences of social software and have integrated several of the factors, which have previously been discussed in isolation. We have also identified a number of additional implications of social software as we have focussed on both the benefits as well as drawbacks of these tools. By drawing on a wide range of initiatives in both further and higher education, we have provided a broad basis for understanding the implications of social software. Hence, our research complements and advances on several of the prior studies that largely focus on individual initiatives.

Our research also creates a number of contributions to educational practice. First of all, our research demonstrates the ambiguity of social software which creates significant benefits, but also risks. Our research raises awareness of the individual educator or decision maker to consider the various issues into their decision-making while adopting social software. We further provide decision makers with a number of practical strategies that help to leverage the potential of social software and to mitigate their risks. We have purposefully introduced the concepts and rationale of SWOT analysis in more detail to allow others to use this systematic method to analyse their individual social software scenario. All of these contributions should help educators and decision makers to better manage the implementation of these applications and to use them in a sustainable way.

\section{Limitations and scope for further research}

The study was based on multiple case research (Miles \& Huberman, 1994) and thematic analysis (Braun \& Clarke, 2006). Although these methods are well recognised for their strength in exploring complex and diverse phenomena, they also introduce a number of limitations to our research. While the use of multiple cases contributes to stability and generalisability of the findings (Yin, 2008), the selection of cases can have an impact on the findings of the research. By focusing on a large 
variety of cases and clear selection criteria, we sought to minimise the case selection bias; nevertheless, we can not exclude that different or additional cases would provide us with additional insights. Further, the quality of thematic analysis can be significantly enhanced by the care and experience of the researcher; however, it still remains open to bias in the identification and categorisation of the themes and patterns. By applying both independent and joint analysis by multiple contributors, we sought to minimise the researcher bias, albeit without being able to fully exclude it. Furthermore, the present analysis considers social software as coherent information technology genre without highlighting the differences between the individual tools. Hence, the SWOT factors may not apply consistently to all types of social software tools to the same extent and the individual characteristics of the applications need to be considered when applying the research findings to a particular application.

One of our main motivations was to explore this emerging social software research domain and to pave the way for further theory generating and theory testing studies, which can directly build up on our research. While we have identified a range of benefits and risks of social software, it would be a very valuable and fruitful area of research to identify the circumstances under which these factors emerge (i.e. under which conditions does social software best exhibit its support to teaching and learning). Hence, an important area for future research is to empirically test the impact our proposed measures have on the implementation and success of the social software initiative. Such studies can further enhance our understanding of the topic in significant ways and support the educators in establishing sustainable social software initiatives. 


\section{Acknowledgement}

The research project was funded by the Joint Information Systems Committee (JISC) under the elearning stream. We gratefully acknowledge funding by JISC and the encouragement and guidance which we received from the JISC programme manager, Heather Williamson. Finally, this project would not have been possible without the support of the participants in a number of institutions all over the UK and whose inputs let to the development of the case studies. 


\section{References}

Benkler, Y. (2002) Coase's penguin, or, Linux and the nature of the firm. The Yale Law Journal. $112(3), 369-446$.

Braun, V., \& Clarke, V. (2006) Using thematic analysis in psychology. Qualitative Research in Psychology 3, 77-101.

Brown, G., Howe, T., Ihbe, M., Prakash, A., \& Borders, K. (2008). Social networks and contextaware spam. Paper presented at the ACM 2008 conference on Computer supported cooperative work.

Cain, J. (2008) Online social networking issues within academia and pharmacy education. American Journal of Pharmaceutical Education. 72(1), 1-7.

Chu, M., \& Meulemans, Y. N. (2008) The Problems and Potential of MySpace and Facebook Usage in Academic Libraries. Internet Reference Services Quarterly. 13(1), 69-85.

Dalsgaard, C. (2006) Social software: E-learning beyond learning management systems. European Journal of Open, Distance and E-Learning. 2.

Dennen, V. P. (2005) From message posting to learning dialogues: Factors affecting learner participation in asynchronous discussion. Distance Education. 26(1), 127-148.

Dennis, A. R., \& Kinney, S. T. (1998) Testing Media Richness Theory in the New Media: The Effects of Cues, Feedback, and Task Equivocality. Information Systems Research. 9(3), 256-274.

Dron, J. (2006). Any color you like, as long as it's Blackboard. Paper presented at the World Conference on E-Learning in Corporate, Government, Healthcare, and Higher Education.

Du, H. S., \& Wagner, C. (2007) Learning with weblogs: Enhancing cognitive and social knowledge construction. IEEE Transactions on Professional Communication. 50(1), 1-16.

Ellison, N. B., Steinfield, C., \& Lampe, C. (2007) The benefits of Facebook" friends:" Social capital and college students' use of online social network sites. Journal of Computer Mediated Communication. 12(4), 1143-1168.

Garrison, D. R., \& Akyol, Z. (2009) Role of instructional technology in the transformation of higher education. Journal of Computing in Higher Education. 21, 19-30.

Garrison, D. R., Anderson, T., \& Archer, W. (1999) Critical inquiry in a text-based environment: Computer conferencing in higher education. The Internet and Higher Education. 2(2-3), 87-105.

Garrison, D. R., \& Arbaugh, J. B. (2007) Researching the community of inquiry framework: Review, issues, and future directions. The Internet and Higher Education. 10(3), 157-172.

Gerhard, J., \& Mayr, P. (2002). Competing in the e-learning environment-strategies for universities. Paper presented at the 35th Annual Hawaii International Conference on Systems Science.

Gross, R., Acquisti, A., \& H. John Heinz, I. (2005). Information revelation and privacy in online social networks. Paper presented at the ACM workshop on Privacy in the electronic society, Alexandria, VA.

Janssen, R. (2002) Evaluation of the organization and financing of the Danish health care system. Health Policy 59, 145-159.

JISC. (2009). Higher Education in a Web 2.0 World [On-line], Available: http://www.jisc.ac.uk/media/documents/publications/heweb20rptv1.pdf 
Johnson, S. D., \& Aragon, S. R. (2003) An instructional strategy framework for online learning environments. New Directions for Adult and Continuing Education(100), 31-43.

Kumar, R., Novak, J., Raghavan, P., \& Tomkins, A. (2004) Structure and evolution of blogspace. Communications of the ACM. 47(12), 35-39.

Mann, B. L. (2008) Social Networking Websites - A Concatenation of Impersonation, Denigration, Sexual Aggressive Solicitation, Cyber-Bullying or Happy Slapping Videos. International Journal of Law and Information Technology.

McLoughlin, C., \& Lee, M. (2007). Social software and participatory learning: Pedagogical choices with technology affordances in the Web 2.0 era. Paper presented at the Ascilite

Miles, M. B., \& Huberman, M. A. (1994). Qualitative data analysis: an expanded sourcebook. Thousand Oaks, California: SAGE Publications, Inc.

Mottet, T. P., Martin, M. M., \& Myers, S. A. (2004) Relationships among perceived instructor verbal approach and avoidance relational strategies and students' motives for communicating with their instructors. Communication Education. 53(1), 116-122.

Parameswaran, M., \& Whinston, A. B. (2007) Research issues in social computing. Journal of the Association for Information Systems. 8(6), 336-350.

Pena-Shaff, J. B., \& Nicholls, C. (2004) Analyzing student interactions and meaning construction in computer bulletin board discussions. Computers and Education. 42(3), 243-265.

Romiszowski, A. J. (2004) How's the e-learning baby? Factors leading to success or failure of an educational technology innovation. Educational Technology. 44(1), 5-27.

Sabbaghi, A., \& Vaidyanathan, G. (2004) SWOT Analysis and Theory of Constraint in Information Technology Projects. Information Systems Education Journal. 2(23), 1-19.

Steffe, L., \& Gale, J. (1995). Constructivism in education. Hillsdale, NJ: Lawrence Erlbaum Associates, Inc.

Trentin, G. (2009) Using a wiki to evaluate individual contribution to a collaborative learning project. Journal of Computer Assisted Learning. 25(1), 43-55.

Yin, R. B. (2008). Case Study Research: Design and Methods (4th ed.). Thousand Oaks, CA: Sage Publications, Inc.

Appendix: List of Social Software Initiatives

\begin{tabular}{|l|l|l|l|}
\hline No. & Institution & $\begin{array}{l}\text { Case study title and social software tools: primary tool(s) followed by } \\
\text { the secondary tool(s) }\end{array}$ & Code \\
\hline 1. & $\begin{array}{l}\text { Anglia Ruskin } \\
\text { University }\end{array}$ & $\begin{array}{l}\text { Computer Gaming and Video Capture in Second Life } \\
\text { 3-D MUVE (Second Life), Blog (WordPress, Blogger), and University's } \\
\text { VLE (Moodle) }\end{array}$ & [ARU] \\
\hline $\mathbf{2 .}$ & $\begin{array}{l}\text { Birmingham City } \\
\text { University }\end{array}$ & $\begin{array}{l}\text { Using Wikis to Support Small Group work } \\
\text { Wiki (PBwiki) and the University's VLE (Moodle) }\end{array}$ & [BCU1] \\
\hline 3. & $\begin{array}{l}\text { Birmingham City } \\
\text { University }\end{array}$ & $\begin{array}{l}\text { Facebook as a Pre-induction Support Tool Social } \\
\text { networking (Facebook) }\end{array}$ & [BCU2] \\
\hline 4. & $\begin{array}{l}\text { London South } \\
\text { Bank University }\end{array}$ & $\begin{array}{l}\text { Photo Publishing with Lulu publishing website with blogs and forums (lulu.com), social } \\
\text { networking (Facebook), blog (WordPress, used in 2006 only) }\end{array}$ & [LSBU] \\
\hline $\mathbf{5 .}$ & $\begin{array}{l}\text { Lancaster } \\
\text { University }\end{array}$ & $\begin{array}{l}\text { Social Networking through Ning on a Distance-learning Programme } \\
\text { Social networking (Ning) }\end{array}$ & [LU] \\
\hline
\end{tabular}




\begin{tabular}{|c|c|c|c|}
\hline 6. & $\begin{array}{l}\text { Northumberland } \\
\text { College }\end{array}$ & $\begin{array}{l}\text { Using a Wiki for Developing a Portfolio and for Communication } \\
\text { Wiki (PBwiki) and the university's VLE (Blackboard) }\end{array}$ & {$[\mathrm{NC}]$} \\
\hline 7. & $\begin{array}{l}\text { Nottingham } \\
\text { Trent University }\end{array}$ & $\begin{array}{l}\text { A Blogging Support System for Trainee Teachers } \\
\text { Blogging (Livejournal) }\end{array}$ & [NTU] \\
\hline 8. & Open University & $\begin{array}{l}\text { OpenStudio: An Online Community for Digital Photography Students } \\
\text { Photo-sharing site (OpenStudio, similar to Flickr) }\end{array}$ & [OU1] \\
\hline 9. & Open University & $\begin{array}{l}\text { Collaborative Learning in a Wiki on a Software Engineering course } \\
\text { Wiki (Moodle's wiki) }\end{array}$ & [OU2] \\
\hline 10. & Open University & $\begin{array}{l}\text { Using Wikis and Video Conferencing on Team Engineering course } \\
\text { Wiki (Moodle's wiki) and video-conferencing tool (Flashmeeting) }\end{array}$ & [OU3] \\
\hline 11. & $\begin{array}{l}\text { Sheffield } \\
\text { University }\end{array}$ & $\begin{array}{l}\text { Blogs and Social Bookmarking for Exploration of Historical Courses } \\
\text { Social bookmarking (Delicious), blog (WordPress) }\end{array}$ & [SU] \\
\hline 12. & $\begin{array}{l}\text { Stockport } \\
\text { College }\end{array}$ & $\begin{array}{l}\text { Photo-sharing on Flickr Photo- } \\
\text { sharing site (Flickr) }\end{array}$ & {$[\mathrm{SC}]$} \\
\hline 13. & $\begin{array}{l}\text { University of } \\
\text { Hertfordshire }\end{array}$ & $\begin{array}{l}\text { Using podcasting to Develop Oral Skills for Physiotherapy Practice } \\
\text { Podcasts and wiki (as a part of StudyNet, MLE) }\end{array}$ & [UH] \\
\hline 14. & $\begin{array}{l}\text { University of } \\
\text { Leeds }\end{array}$ & $\begin{array}{l}\text { Blogs, Wikis and Social Bookmarking to Support Web-based Research } \\
\text { Social bookmarking (Bibsonomy), blog (Elgg), wiki (LeedsWiki based on } \\
\text { MediaWiki) }\end{array}$ & [UL] \\
\hline 15. & $\begin{array}{l}\text { University of } \\
\text { Manchester }\end{array}$ & $\begin{array}{l}\text { Social Networking and Community-building in Dentistry Courses Blog } \\
\text { (Edublogs), social networking (Facebook), podcasts }\end{array}$ & [UM] \\
\hline 16. & $\begin{array}{l}\text { University of } \\
\text { Westminster }\end{array}$ & $\begin{array}{l}\text { Social Networking: Connect-ing Students and Staff } \\
\text { Social networking (Elgg) }\end{array}$ & {$[\mathrm{UW}]$} \\
\hline 17. & $\begin{array}{l}\text { Nottingham } \\
\text { University }\end{array}$ & $\begin{array}{l}\text { Google Earth: Practical Exercises in Geographic Information Science } \\
\text { GoogleEarth }\end{array}$ & {$[\mathrm{NU}]$} \\
\hline 18. & Open University & $\begin{array}{l}\text { Using Social Bookmarking: Tools for Finding Things Again } \\
\text { Social bookmarking (Delicious, Furl and Simpy) }\end{array}$ & [OU4] \\
\hline 19. & Open University & $\begin{array}{l}\text { Supporting a Group of Distance-learning Students on Skypecast Voice } \\
\text { over Internet Protocol (Skype) and Skypecast }\end{array}$ & [OU6] \\
\hline 20. & $\begin{array}{l}\text { Portsmouth } \\
\text { University }\end{array}$ & $\begin{array}{l}\text { Using Twitter to Support Students and their Projects Micro- } \\
\text { blogging (Twitter) }\end{array}$ & {$[\mathrm{PU}]$} \\
\hline
\end{tabular}

